\title{
The Developmental Cycle of Chlamydia trachomatis in McCoy Cells Treated with Cytochalasin B
}

\author{
By PENNY STIRLING \\ Department of Bacteriology, University of Bristol, \\ Bristol BS8 I TD \\ AND SHIRLEY RICHMOND \\ Public Health Laboratory, Kingsdown, Bristol BS2 $8 E L$
}

(Received 20 October 1976)

\begin{abstract}
SUMMARY
The growth of a genital trachoma-inclusion conjunctivitis agent strain of Chlamydia trachomatis in McCoy cells treated with cytochalasin B was studied by quantitative infectivity estimations and by light and electron microscopy. Provided that infection of the monolayer was initiated by centrifuging the infectious particles on to the cells before incubation, this chlamydial strain grew as fast and to as high a titre [approximately $10^{7}$ inclusion-forming units (i.f.u.) per culture] as those chlamydiae which infect cell cultures in vitro without centrifugation. Each i.f.u. inoculated yielded approximately 600 i.f.u., and extracellular infectivity was detected soon after intracellular infectivity appeared. Inclusions were recognized by fluorescent antibody staining techniques early in the developmental cycle when cultures were not infectious and when only reticulate bodies were seen by electron microscopy. Inclusions were recognized in Giemsa-stained preparations examined by dark ground microscopy only when elementary bodies appeared in the inclusions. Iodine staining was not a reliable indicator either of the number of inclusions present or of their infectivity.
\end{abstract}

\section{INTRODUCTION}

All chlamydiae undergo a unique developmental cycle in the cytoplasm of eukaryotic cells. The elementary body, the infectious form of the chlamydial agent, is a metabolically inert, rigid-walled particle about $300 \mathrm{~nm}$ in diameter. Once within the cell, it becomes reorganized into a larger thin-walled form about $\mathrm{I} \mu \mathrm{m}$ in diameter, the reticulate or initial body, which is non-infectious but metabolically active. The reticulate body multiplies by fission to form a microcolony of pleomorphic chlamydial forms which lie within a cytoplasmic vacuole, recognized by light microscopy as a basophilic cytoplasmic inclusion. Division is followed by reorganization of reticulate bodies into smaller intermediate forms and then into elementary bodies. Finally rupture of the mature inclusion releases a fresh generation of infectious chlamydial agents into the extracellular environment.

This developmental cycle was first described in light microscopy studies on Chlamydia psittaci by Bedson \& Bland (1932) and Bland \& Canti (1935). Subsequent light and electron microscopy studies confirmed and extended these workers' observations (e.g. Litwin et al., 196I; Higashi, Tamura \& Iwanaga, 1962; Higashi, 1964) and showed that organisms belonging to the $C$. trachomatis species underwent similar morphological changes during their intracellular development (Rake \& Jones, 1942; Bernkopf, Mashiah \& Becker, 1962; Armstrong \& Reed, 1964; Higashi, 1964, 1965; Kramer \& Gordon, 197I). In the latter 
studies, either lymphogranuloma venereum (LGV) or 'fast' growing trachoma-inclusion conjunctivitis (TRIC) agent strains of $C$. trachomatis were used. Such 'fast' growing strains have immunological and biological characteristics of LGV strains rather than of TRIC agents (Wang \& Grayston, I97I). The developmental cycle of true TRIC agents has been much less extensively studied in vitro because of the difficulty experienced in growing these organisms in cell culture. Recently, however, primary isolation of TRIC agents from the infected human conjunctiva and genital tract has been described in various cell culture systems (Gordon et al., 1969; Kuo et al., 1972; Hobson et al., 1974; Sompolinsky \& Richmond, 1974; Wentworth \& Alexander, 1974). In all these methods, centrifuging the infectious particles on to the cell monolayer before incubation is essential.

This paper describes the complete developmental cycle of a genital strain of C. trachomatis, TRIC serotype E, in cytochalasin-treated McCoy cells, studied by quantitative infectivity titrations and by electron, light, dark ground and fluorescence microscopy. The results suggest that the cultural differences between genital TRIC agents and the other chlamydiae which grow more readily in cell cultures in vitro, lie largely in the initial stages of cell penetration, rather than in the kinetics of their intracellular growth cycle, or in the release of infectious chlamydial particles from the cells.

\section{METHODS}

Organism. A genital strain of $C$. trachomatis, TRIC serotype E, designated TI8I, which had been passed eight to ten times in McCoy cell cultures, was used throughout. The origin of this strain has been described (Sompolinsky \& Richmond, 1974). Stocks were made from the cells and supernatant fluids of heavily infected McCoy cell cultures and were stored at $-70^{\circ} \mathrm{C}$ in $10 \%(\mathrm{w} / \mathrm{v})$ sorbitol (Richmond, 1974). Inocula of strain TI8I containing approximately $2 \times 10^{4}$ inclusion-forming units (i.f.u.) per culture were used throughout, except cultures harvested early in the developmental cycle (between o and Io $\mathrm{h}$ incubation) for examination by electron microscopy were inoculated with approximately $5 \times 10^{5}$ i.f.u. per culture.

Cell cultures. McCoy cells, a continuous line of mouse fibroblasts (Gordon et al., 1972), were grown and maintained as described by Richmond (1974), and cytochalasin-treated McCoy cell cultures for growth of chlamydiae were prepared as described by Sompolinsky \& Richmond (1974). Briefly, monolayers of McCoy cells were grown for 3 days at $35^{\circ} \mathrm{C}$ on circular glass coverslips in flat-bottomed plastic vials in growth medium containing I $\mu \mathrm{g}$ cytochalasin B ml ${ }^{-1}$ (Ralph Emmanuel, Wembley, Middlesex, HAo I PY). Growth medium was replaced with $\mathrm{I} \mathrm{ml}$ maintenance medium containing I $\mu \mathrm{g}$ cytochalasin $\mathrm{B}$ before inoculation of chlamydiae. After inoculation, all cultures were centrifuged at $33^{\circ} \mathrm{C}$ for $\mathrm{I} \mathrm{h}$ at $3000 \mathrm{~g}$ before incubating at $35^{\circ} \mathrm{C}$.

Growth of chlamydiae. Since TRIC agents only complete one developmental cycle in cell cultures in vitro, no procedures were necessary to prevent secondary growth cycles. The culture techniques for both the one-step growth curve and the infectivity assay system were similar to those used in this laboratory for primary isolation of chlamydiae (Sompolinsky \& Richmond, 1974).

(i) One-step growth curve. Inoculated, centrifuged McCoy cell cultures were harvested between $\mathrm{o}$ and $96 \mathrm{~h}$ after centrifugation and stored at $-70{ }^{\circ} \mathrm{C}$ in $10 \%(\mathrm{w} / \mathrm{v})$ sorbitol (Richmond, 1974). For each sampling time, pooled material from two cultures was used to assess the infectivity of both the cells and the culture fluid, and that from two more cultures, the total infectivity. Harvested cells were frozen and thawed twice to release 
intracellular chlamydial particles before estimating their infectivity. To estimate the infectivity recoverable from the supernatant fluid after centrifuging, cultures which were harvested after $\mathrm{o}$ and $5 \mathrm{~h}$ incubation were not subjected to a change of maintenance medium. The existing medium was pipetted gently over the cell monolayer several times before it was withdrawn, to dislodge any chlamydial particles still on the surface of the cells. In all remaining cultures the medium was removed after $5 \mathrm{~h}$ incubation, and the cells were washed three times in sterile phosphate-buffered saline $\mathrm{pH} 7 \cdot 2$ (PBS) and reincubated in $0.75 \mathrm{ml}$ fresh maintenance medium containing $1 \mu \mathrm{g}$ cytochalasin B $\mathrm{ml}^{-1}$.

(ii) Infectivity assay. Infectivity was assessed by inoculating, again with centrifugation, appropriate dilutions of the harvested cell culture material on to fresh cytochalasin-treated McCoy cell cultures, followed by incubation for $68 \mathrm{~h}$ at $35^{\circ} \mathrm{C}$. Cell monolayers were then fixed, stained with Giemsa and scanned by dark ground microscopy. The total number of i.f.u. per culture was calculated from the total number of inclusions per coverslip (mean of count on three coverslips) (Richmond, 1975). Similarly, the infectivity of the original inoculum of strain TI8I was measured by inoculating three cell cultures with a $1 \mathrm{O}^{-2}$ dilution of the original inoculum and counting the inclusions present in the monolayers $68 \mathrm{~h}$ later.

Preparation of material for electron microscopy. Cells from eight to ten cell cultures were gently removed from the coverslips with a Pasteur pipette, and the resulting suspensions were pooled and centrifuged at $300 \mathrm{~g}$ for $5 \mathrm{~min}$ to deposit the cells. The supernatant fluid was discarded, and the cells were washed by resuspension in sterile PBS and centrifuged at $1000 \mathrm{~g}$ for $5 \mathrm{~min}$. The supernatant fluid was removed and the pelleted cells were fixed in $2.5 \%(\mathrm{v} / \mathrm{v})^{\circ}$ glutaraldehyde in $0.1 \mathrm{M}$-cacodylate buffer $\mathrm{pH} 7 \cdot 2$. The pellets were then cut into portions, rinsed in buffer, postfixed in $1 \%(w / v)$ osmium tetroxide in $0 \cdot 1 \mathrm{M}$-cacodylate buffer $\mathrm{pH} 7 \cdot 2$, dehydrated in a graded ethanol series followed by propylene oxide, and finally infiltrated and embedded in Araldite. Sections were cut using an LKB III ultramicrotome with glass knives, mounted on Formvar-coated grids, double stained with uranyl acetate and lead citrate and examined in a Philips EM 20I electron microscope.

Light microscopy methods for detecting inclusions. (i) Giemsa stain. Methanol-fixed monolayers of cells were stained in Giemsa (Richmond, 1974) and examined by dark ground microscopy. (ii) Iodine stain. Methanol-fixed cell monolayers were stained in iodine (Gordon et al., 1969) and examined by light microscopy. (iii) Fluorescent antibody $(F A B)$ staining. Monolayers of cells on glass coverslips were fixed in methanol at $-20{ }^{\circ} \mathrm{C}$ for $20 \mathrm{~min}$, then mounted on slides in DePeX with the cells uppermost. Cells were stained by indirect immunofluorescence, using human or rabbit antisera both of which contained complement-fixing antibodies to the chlamydial group antigen. The rabbit antiserum, $\mathrm{R} 367$, was produced by immunizing a rabbit with a $C$. trachomatis strain, serotype $\mathrm{E}$ (Sowa, Collier \& Sowa, 1971). The human antiserum was obtained from a patient with clinical and serological evidence of psittacosis. In each of these sera, the complementfixing and fluorescent chlamydial antibody titres were similar, indicating that these antibodies were directed solely against the chlamydial group antigen (Richmond \& Caul, 1975), and neither serum fluoresced with uninfected McCoy cells. Control negative rabbit and human sera were included in the test. The cells were incubated with the sera for $\mathrm{I} \mathrm{h}$ at $36{ }^{\circ} \mathrm{C}$, washed well in PBS, dried, treated with either fluorescein-conjugated anti-human or anti-rabbit immunoglobulin (Wellcome Reagents) as appropriate, and re-incubated for I h. Cells were washed well in PBS and examined under a Reichert Zetopan microscope with a wide-field dark ground condenser, an HBO 200 mercury vapour lamp, a Reichert E2 interference filter and an $\mathrm{SP}_{2}$ barrier filter. (iv) Acridine orange stain. Monolayers of cells were fixed in acid/alcohol and stained with acridine orange (Pollard \& Starr, 1962). 

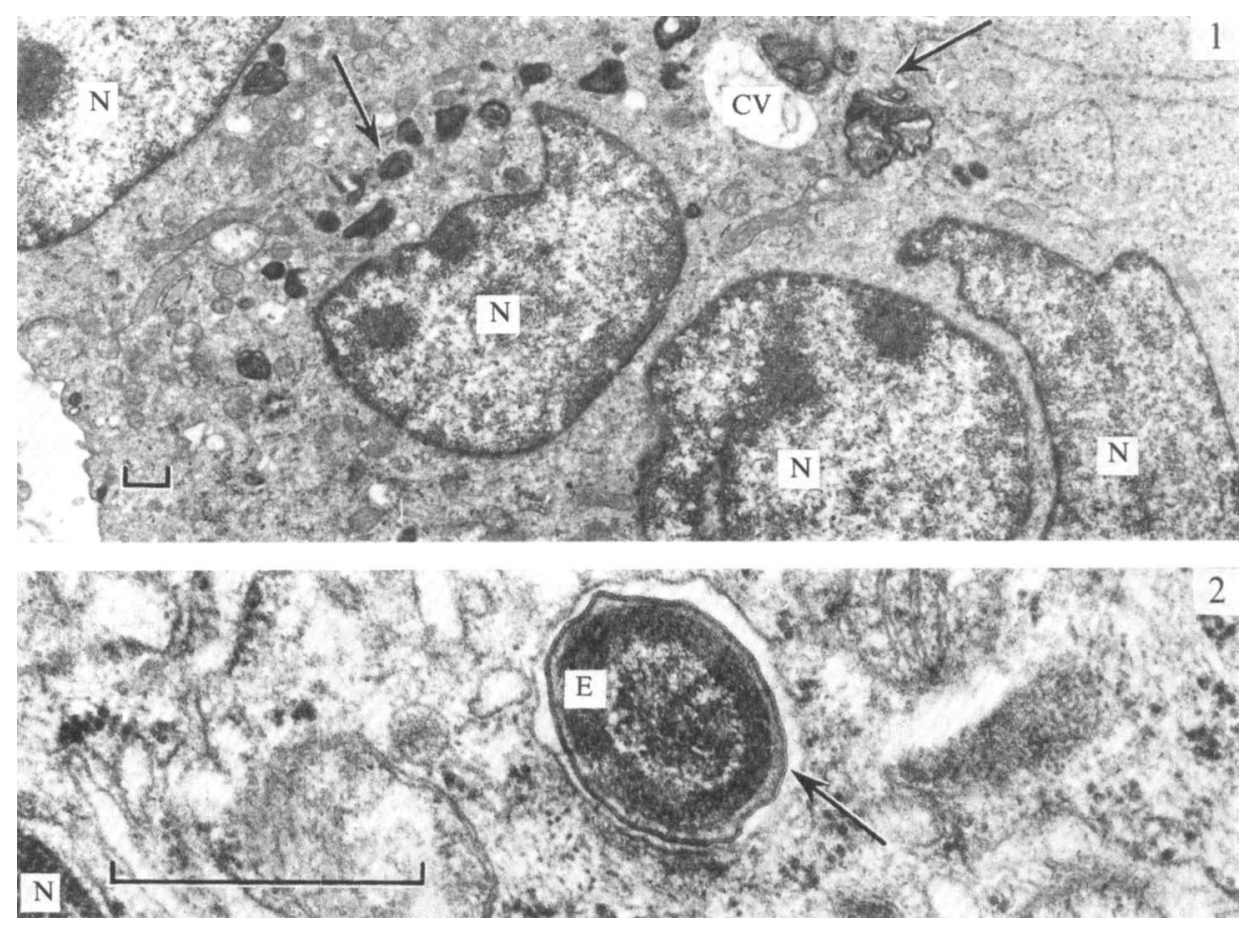

Bar markers represent $500 \mathrm{~nm}$.

Fig. I. Cytochalasin-treated McCoy cell showing four nuclei (N), a cytoplasmic vacuole (CV) and lysosomal activity (arrows).

Fig. 2. Cytochalasin-treated McCoy cell immediately after centrifugation showing an intracytoplasmic elementary body (E) lying within a phagocytic vacuole (arrow). The elementary body is already near to the nucleus $(\mathrm{N})$ and its centre is less condensed than its periphery.

Preparations were examined by ultraviolet light, in the same system as that used for examining the FAB-stained cells.

All preparations were examined at a magnification of 400 .

\section{RESULTS}

Effect of cytochalasin B on McCoy cell morphology

The prevention of cytoplasmic cleavage, which has been reported previously in both fibroblast and lymphocyte cell cultures treated with cytochalasin B (Carter, 1967; Ridler \& Smith, I968), was confirmed. Cytoplasmic division of McCoy cells was inhibited in the presence of $\mathrm{I} \mu \mathrm{g}$ cytochalasin $\mathrm{B} \mathrm{ml} \mathrm{m}^{-1}$, whereas mitosis continued so that a population of multinucleated giant cells was produced. Vacuolation of the cytoplasm and considerable lysosomal activity were frequently seen in the cytoplasm of these cells (Fig. I). C type virus particles, known to be present in the McCoy cell line (Kajima, Sharon \& Pollard, I967), were also often observed.

\section{Effect of centrifugation}

Only $2 \%$ of the infectivity of the original inoculum could be recovered from the cell medium immediately after centrifugation, suggesting that during centrifugation at $33^{\circ} \mathrm{C}$ the chlamydial particles either adsorb firmly to the cell surface or penetrate the cytoplasm. 


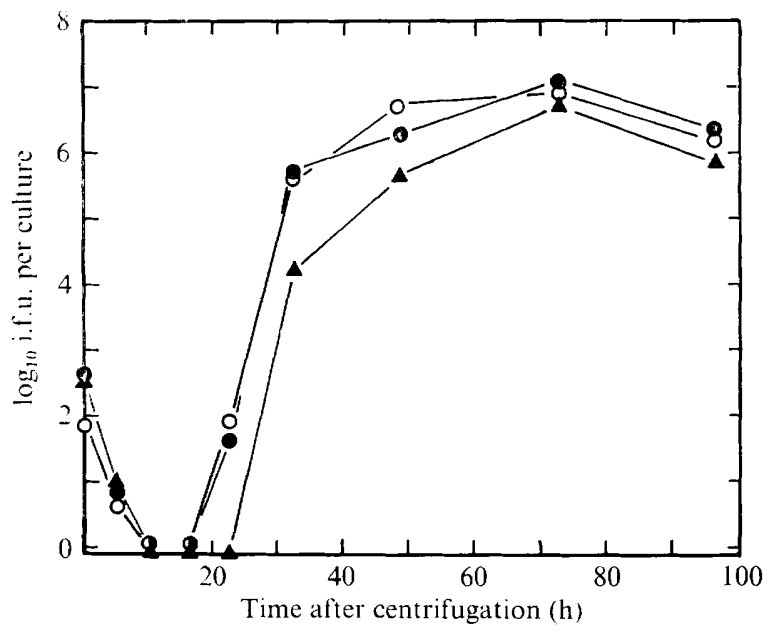

Fig. 3. One-step growth curve of $C$. trachomatis, TRIC serotype E, in cytochalasin-treated McCoy cells. The input dose per culture was $2.085 \times 10^{4}$ i.f.u. $O$, Total infectivity; $O$, cellular infectivity; $\boldsymbol{\Delta}$, infectivity in supernatant fluid.

Evidence that penetration rather than adsorption had occurred was obtained by electron microscopy: after centrifugation but before incubation of the cultures, elementary bodies were not seen attached to the surface of the cells but were seen lying in cytoplasmic vacuoles well within the cytoplasm of the host cell, often already adjacent to the cell nucleus (Fig. 2). The centre of these elementary bodies was less condensed than their peripheral cytoplasm, and the eccentric, electron-dense nucleoid which is prominent in many of the progeny elementary bodies (Figs 9, Io and II) was not visible. At this time only $0.3 \%$ of the infectivity of the inoculum could be recovered from the cells. Comparison with inoculated cell cultures which were not centrifuged demonstrated the importance of centrifugation in achieving infection of the monolayer. No intracytoplasmic chlamydial particles could be seen by electron microscopy in uncentrifuged cultures kept at $33{ }^{\circ} \mathrm{C}$ for I $\mathrm{h}$ and, after incubation at $35^{\circ} \mathrm{C}$ for 3 days, these cultures yielded only $0 . \mathrm{I} \%$ of the number of inclusions produced in replicate centrifuged cultures.

\section{One-step growth curve}

The production of i.f.u. in chlamydia-infected cells during one chlamydial developmental cycle is shown in Fig. 3. Very low levels of infectivity could be recovered from the cells immediately after centrifugation and after $5 \mathrm{~h}$ incubation, but during the next 10 to $15 \mathrm{~h}$ the cultures were not infectious. Low levels of i.f.u. were recovered from the cells after $22 \mathrm{~h}$, and the infectivity then rose sharply during the next $10 \mathrm{~h}$. By $32 \mathrm{~h}$, i.f.u. were also recovered from the medium. Maximum infectivity was detected at $72 \mathrm{~h}$, and by then infectivity in the culture fluid nearly equalled that recovered from the cells. This probably represented true extracellular infectivity, since separate experiments established that lowspeed centrifugation of the culture medium to precipitate any cells in suspension did not reduce the infectivity of the supernatant fluid harvested at 32,48 and $72 \mathrm{~h}$. By $72 \mathrm{~h}$ there was an estimated yield of approximately 600 i.f.u. from each i.f.u. inoculated. Infectivity thereafter gradually declined, and a second developmental cycle was not initiated spontaneously. 

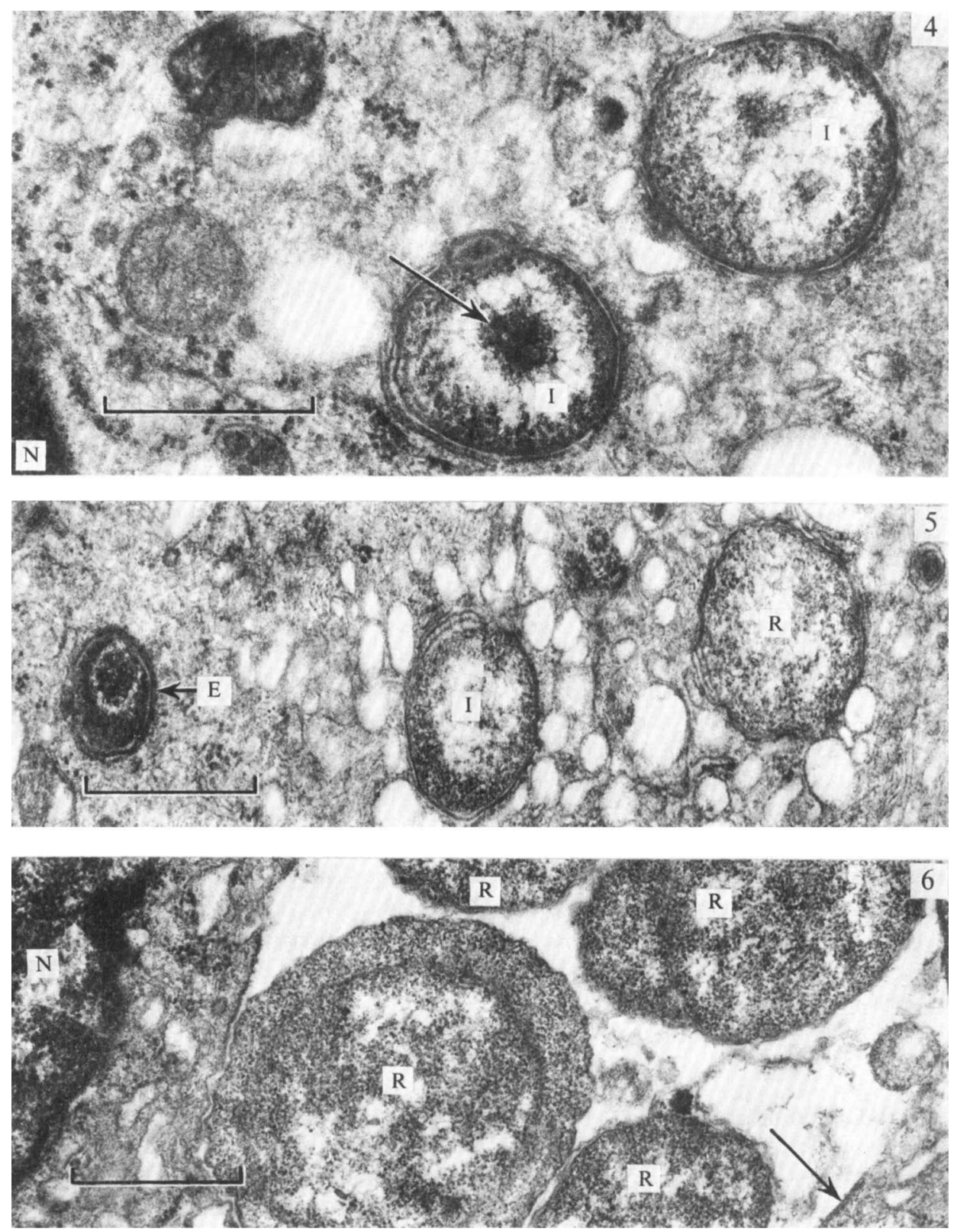

Bar markers represent $500 \mathrm{~nm}$.

Fig. $4.3 \mathrm{~h}$ after centrifugation: two intermediate chlamydial forms (I), one with an electron-dense centre (arrow), lie in separate vacuoles near the nucleus $(\mathrm{N})$. They are in the process of transformation from elementary bodies to reticulate bodies.

Fig. $5.5 \mathrm{~h}$ after centrifugation: three chlamydial organisms lie in separate vacuoles at different stages of transformation. E, Elementary body; I, intermediate form with an electron-translucent, fibrillar centre; $R$, reticulate body, probably still in the process of enlarging.

Fig. 6. Io h after centrifugation: four reticulate bodies (R) lie within a single vacuole next to the nucleus $(\mathrm{N})$, forming an early chlamydial inclusion. The limiting membrane of the inclusion (arrow) and the lack of rigidity of the outer envelope of the reticulate bodies are seen. 

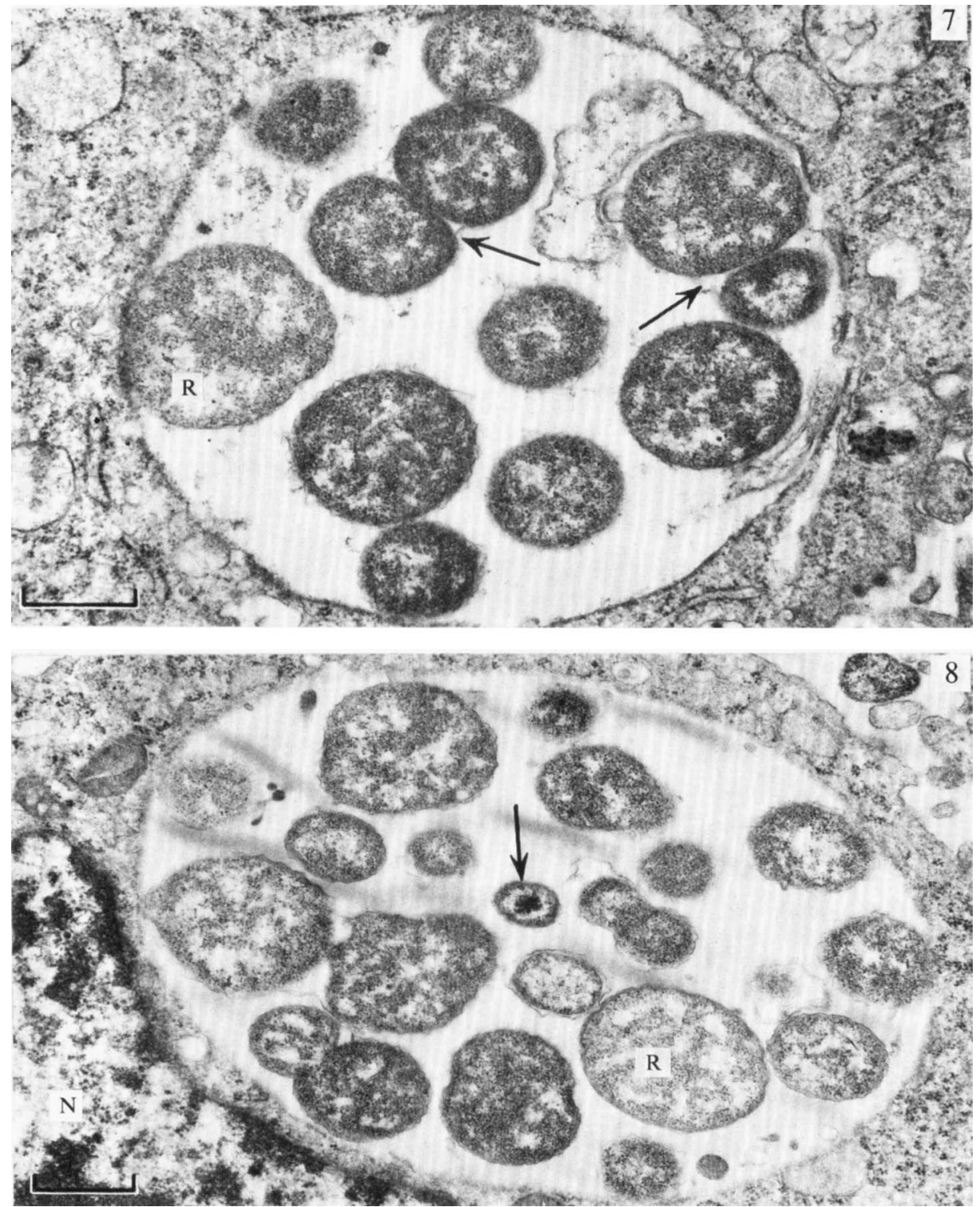

Bar markers represent $500 \mathrm{~nm}$.

Fig. 7. Inclusion after $16 \mathrm{~h}$ : reticulate bodies (R), some undergoing division (arrows), are present.

Fig. 8. Inclusion after $22 \mathrm{~h}$ : dividing reticulate bodies still predominate but an intermediate form (arrow) is also present. The inclusion is indenting the nucleus $(\mathrm{N})$.

\section{The developmental cycle studied by electron microscopy}

After centrifugation, the reorganization of the elementary bodies into reticulate bodies was a relatively slow process which took at least $5 \mathrm{~h}$. After incubation for $3 \mathrm{~h}$, many of the electron-dense elementary bodies had been replaced by slightly larger, intermediate chlamydial forms (Fig. 4), similar to those seen in later stages of the developmental cycle 


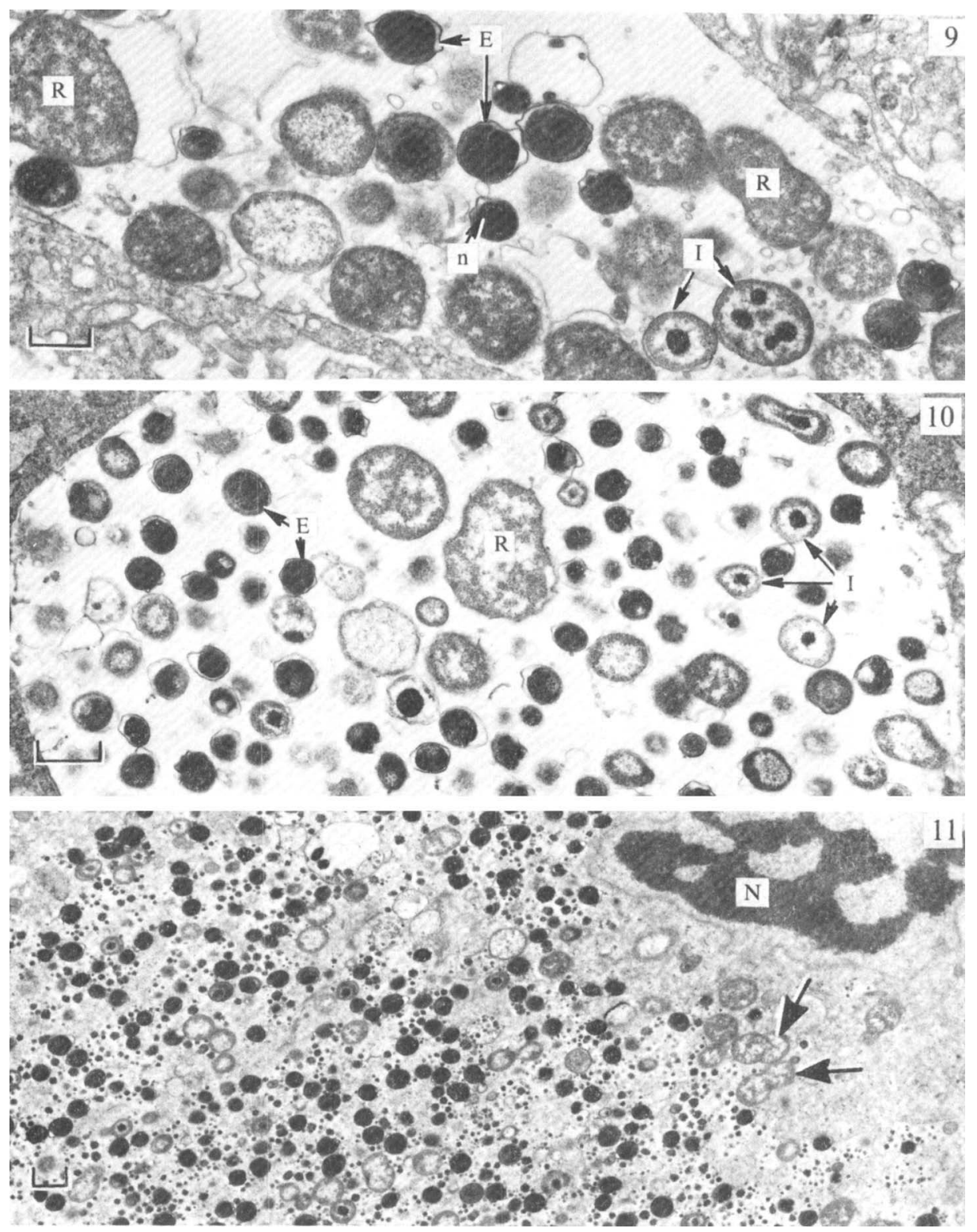

Bar markers represent $500 \mathrm{~nm}$.

Fig. 9. Part of an inclusion after $32 \mathrm{~h}$ : reticulate bodies $(\mathrm{R})$, intermediate forms $(I)$ and elementary bodies (E) are all present. Arrows indicate the double-membraned, limiting envelopes of elementary bodies and intermediate forms. $n$, eccentric, electron-dense nucleoid.

Fig. 10. Part of an inclusion after $48 \mathrm{~h}$ : elementary bodies (E) predominate, but dividing reticulate bodies $(\mathrm{R})$ and intermediate forms (I) are still present.

Fig. I1. Section after $72 \mathrm{~h}$ : a discrete inclusion can no longer be seen and pleomorphic chlamydial forms are distributed throughout the cytoplasm. Despite the late stage in the developmental cycle, dividing reticulate bodies are still present (arrows). The electron-dense material distributed between the chlamydiae is probably the carbohydrate matrix. 
after division had occurred (Figs 9, Io and I I). The interior of these intermediate forms was less condensed than that of elementary bodies; they frequently had an electron-dense centre separated from the peripheral cytoplasm by an electron-translucent zone bridged by fibrils, but in larger, less condensed particles the dense centre was not obvious (Fig. 4). By $5 \mathrm{~h}$, some particles were still recognizable as elementary bodies or intermediate forms, but larger particles, with the granular appearance and thin, double-membraned envelope typical of reticulate bodies, were beginning to appear (Fig. 5). However, particles still appeared singly in individual cytoplasmic vacuoles, and no evidence that division had occurred at this stage was obtained. By $10 \mathrm{~h}$, early chlamydial inclusions consisting of small numbers of reticulate bodies within a single, clearly defined vacuole could be seen (Fig. 6). The size of the inclusions and the number of particles within them both increased rapidly within the next few hours. Reticulate bodies, often actively dividing, were the only chlamydial particles seen in $\mathrm{I} 6 \mathrm{~h}$ inclusions (Fig. 7), and they were still the predominant form after $22 \mathrm{~h}$, although occasional intermediate forms were seen at this stage (Fig. 8). By $32 \mathrm{~h}$, inclusion contents were very pleomorphic; dividing reticulate bodies were still found, but intermediate and dense-centred forms were also present (Fig. 9). Although no longer predominant, dividing reticulate bodies and intermediate forms were still present in mature inclusions after $48 \mathrm{~h}$ incubation (Fig. 10); even in cells where the inclusion contents were about to be released from the cell (Fig. I I), considerable numbers of reticulate bodies, some apparently still undergoing division, were present.

\section{Recognition of inclusions by light microscopy}

Appreciable numbers of very small inclusions could be recognized by $F A B$ staining after $10 \mathrm{~h}$ incubation. By $\mathrm{I} 6 \mathrm{~h}$ many of the cells contained brightly fluorescing, small inclusions which increased considerably in size during the next 2 days.

Inclusions could also be recognized with acridine orange which stains RNA red and DNA green; inclusions were stained red early in the developmental cycle, when reticulate bodies were the sole or predominant chlamydial form, and they could be recognized in some cells by $10 \mathrm{~h}$. By $22 \mathrm{~h}$ they had increased in number and in size. As the inclusions enlarged there was a transition in the staining properties of the inclusion contents from red to greenish-brown. Even after $72 \mathrm{~h}$, however, inclusions were often partially stained red, frequently with coaser red granules at the periphery and a finer granular, green-staining material in the centre.

The autofluorescence of mature Giemsa-stained inclusions examined by dark ground microscopy is a well recognized phenomenon. In the present study, inclusions could not be identified by this technique until appreciable numbers of elementary bodies were visible in inclusions examined by electron microscopy, which suggests it is the elementary bodies rather than the reticulate bodies which autofluoresce in this system. Giemsa-stained preparations were not examined for inclusions by conventional light microscopy, since under normal illumination it is often difficult to distinguish clearly between small inclusions and the cytoplasmic vacuoles which are frequently present in cytochalasin-treated McCoy cells (Fig. I).

Inclusions that were stained pale reddish-brown with iodine were first seen at $32 \mathrm{~h}$, and the density and size of these iodine-stained inclusions usually increased after longer incubation periods. However, the appearance and density of the iodine-stained material was not consistent, and inclusions which were not stained with iodine were frequently seen at both 48 and $72 \mathrm{~h}$. 


\section{DISCUSSION}

The genital TRIC agent TI8I used in this work grew efficiently in McCoy cells treated with cytochalasin B. The effect of cytochalasin on the growth of chlamydiae is not yet fully understood; it may enhance chlamydial growth by reducing the cellular requirements for metabolites whic $h$ are essential for both cells and parasite (Richmond, 1976). Possibly cytochalasin also alters the McCoy cell membrane thus facilitating both the uptake and the release of elementary bodies by the host cell.

Previous studies demonstrated unequivocally that centrifuging was necessary to initiate the intracellular development of TRIC agents in cell culture systems in vitro (e.g. Weiss \& Dressler, 1960; Kuo et al., 1972; Johnson \& Hobson, 1976). The present work confirmed this. In these experiments the same centrifugation procedure was used both for initiating infection in the inoculated monolayers and for assaying infectivity of the supernatant fluid immediately after centrifugation. Most of the infectious organisms detected under these conditions penetrated the cells during centrifugation, since only $2 \%$ of the inoculum could be recovered from the supernatant fluid after centrifugation. Moreover, the low recovery of intracellular infectivity $(0.3 \%$ of the inoculum) immediately after centrifugation, even though intracellular elementary bodies were detected by electron microscopy (Fig. 2), suggests that reorganization of elementary bodies into reticulate bodies had begun during centrifugation, so that many of the intracellular chlamydial particles were already noninfectious. There was also some ultrastructural evidence that reorganization had started in that the centres of these intracellular elementary bodies (Fig. 2) were less condensed than those of mature, progeny forms (Figs 9, Io and II).

After centrifugation, the intracellular development of strain TI8I was similar to that reported for other chlamydiae. The organisms passed through a non-infectious stage which corresponded both with the time that reticulate bodies only were found within the inclusions (Figs 6 and 7), and with the demonstration of RNA within the inclusions.

As inclusions were also clearly visible by FAB-staining at this stage, the reticulate bodies, as well as the elementary bodies, probably possess the lipopolysaccharide antigen common to all members of the genus. This confirms the earlier observation of Collier (I962) that this antigen, detected by the complement fixation test, was present during the non-infectious stage of the chlamydial developmental cycle. Its presence in the reticulate bodies may explain why inclusions are sometimes demonstrated by FAB staining of clinical material from which infectious organisms cannot be recovered, and in which inclusions are not stained by Giemsa or iodine (Schachter et al., 1970).

The appearance of elementary bodies in sections examined by electron microscopy coincided with the detection of appreciable levels of infectivity in the cultures, and with the recognition of inclusions by Giemsa staining and often by iodine staining. Unlike the other staining methods used, iodine stains the carbohydrate matrix of the inclusion rather than the organisms themselves. The significance of this carbohydrate is not yet understood. Its production is dependent on a parasite rather than a host-cell enzyme system (Jenkin \& Fan, I97I); it was not present during the non-infectious phase of the cycle of a 'fast' growing TRIC agent (Evans, I972); and in the present study it was also not essential for the maturation of the inclusions. Moreover, previous experiments in this laboratory showed that in the presence of low concentrations of sulphonamide, inclusions are formed which contain the carbohydrate that is stained by iodine, but no infectious organisms (unpublished observations). Therefore, neither the presence nor absence of inclusions stained by iodine is a reliable indicator of the infectivity of the inclusion. 
The kinetics of the developmental cycle of strain $\mathrm{TI} 8 \mathrm{I}$ were similar to those reported both for $C$. psittaci strains (Litwin et al., I961; Higashi et al., 1962) and for 'fast' growing C. trachomatis strains (Bernkopf \& Mashiah, I962; Furness \& Fraser, 1962; Collier, 1962) and the yield of infectious organisms (about $10^{7}$ i.f.u. per culture) was also comparable. Despite the fact that the contents of even mature inclusions are very pleomorphic and still contain many non-infectious forms (Figs 10 and II), the estimated yield of 600 i.f.u. per inclusion shows that many infectious organisms were also present. This compares well with the yields of 278 i.f.u. per inclusion reported by Evans (1972) with a 'fast' growing strain propagated in BHK-2I cells, and of 400 to 500 plaque-forming units per infected cell reported by Higashi et al. (1962) with a $C$. psittaci strain grown in L cells.

In contrast to previous reports on C. trachomatis strains grown in HeLa cells (Furness, Graham \& Reeve, 1960; Jenkin, 1966), the infectious particles of strain TI8I grown in cytochalasin-treated McCoy cells were not particularly cell-associated. Infectivity appeared in the supernatant fluid soon after it appeared in the cells (Fig. 3). This extracellular infectivity could have been due either to disintegration of a proportion of the infected cells after about $30 \mathrm{~h}$ incubation, or to release of elementary bodies from infected cells before the rupture of the inclusions themselves. The factors governing release of infectivity from chlamydia-infected cells are not known. Todd \& Storz (1975) showed that lysis of cells infected with $C$. psittaci was mediated by release of lysosomal enzymes into the host-cell cytoplasm towards the end of the developmental cycle, but the mechanisms regulating this lysosomal response are not understood.

The reputation that TRIC agents have for growing poorly in tissue culture systems appears to be due largely to the inability of the majority of the infectious particles to penetrate cells spontaneously in vitro. If the organisms are brought in contact with susceptible cell monolayers by centrifugation, genital chlamydiae will develop intracellularly as fast and to as high a titre as other chlamydiae. However, the molecular and biochemical processes which control the chlamydial developmental cycle within cells are still largely unknown.

We are grateful to Dr S. K. R. Clarke for her helpful advice and criticism, to Professor L. H. Collier, The Lister Institute, Elstree, Hertfordshire, for the gift of the rabbit serum R367, and to Mr V. L. Annett for expert technical assistance.

\section{REFERENCES}

Armstrong, J. A. \& Reed, S. E. (1964). Nature and origin of initial bodies in lymphogranuloma venereum. Nature, London 201, 37I-373.

Bedson, S. P. \& Bland, J. O. W. (1932). A morphological study of psittacosis virus with the description of a developmental cycle. British Journal of Experimental Pathology 13, 46I-466.

BERnkOPF, H. \& MASHIAH, P. (1962). The growth cycle of a trachoma agent in FL cell cultures. Journal of Immunology 88, 570-57I.

Bernkopf, H., Mashiah, P. \& Becker, Y. (1962). Correlation between morphological and biochemical changes and the appearance of infectivity in FL cell cultures infected with trachoma agent. Annals of the New York Academy of Sciences 98, 62-8I.

Bland, J. O. W. \& CANTI, R. G. (1935). The growth and development of psittacosis virus in tissue cultures. Journal of Pathology and Bacteriology 40, 231-24I.

CARTER, S. B. (1967). Effects of cytochalasins on mammalian cells. Nature, London 213, 261-264.

Collier, L. H. (1962). Growth characteristics of inclusion blennorrhoea virus in cell cultures. Annals of the New York Academy of Sciences 98, 42-49.

Evans, A. (1972). The development of TRIC organisms in cell cultures during multiple infection. Journal of Hygiene 7o, 39-48.

Furness, G. \& Fraser, E. F. (1962). One-step growth curves for inclusion blennorrhoea virus in HeLa cell monolayers. Journal of General Microbiology 27, 299-304. 
Furness, G., Graham, D. M. \& Reeve, P. (1960). The titration of trachoma and inclusion blennorrhoea viruses in cell cultures. Journal of General Microbiology 23, 613-619.

Gordon, F. B., Harper, I. A., Quan, A. L., Treharne, J. D., Dwyer, R. St. C. \& Garland, J. A. (I969). Detection of Chlamydia (Bedsonia) in certain infections of man. Laboratory procedures: comparison of yolk sac and cell culture for detection and isolation. Journal of Infectious Diseases 120, 45I-462.

Gordon, F. B., Dressler, H. R., Quan, A. L., MCQuilkin, W. T. \& Thomas, J. I. (1972). Effect of ionizing irradiation on susceptibility of McCoy cell cultures to Chlamydia trachomatis. Applied Microbiology 23, $123-129$.

Higashi, N. (1964). The mode of reproduction of the psittacosis-lymphogranuloma-trachoma (PLT) group viruses. International Review of Experimental Pathology 3, 35-64.

HigashI, N. (1965). Electron microscopic studies on the mode of reproduction of trachoma virus (psittacosis virus) in cell cultures. Experimental and Molecular Pathology 4, 24-39.

Higashi, N., Tamura, A. \& Iwanaga, M. (1962). Developmental cycle and reproductive mechanism of the meningopneumonitis virus in L cells. Annals of the New York Academy of Sciences 98, 100-I $2 \mathrm{I}$.

Hobson, D., Johnson, F. W. A., ReEs, E. \& TAIT, I. A. (1974). Simplified method for diagnosis of genital and ocular infections with chlamydia. Lancet ii, 555-556.

Jenkin, H. M. (I966). The continuous passage of agents of trachoma in cell culture. I. Characteristics of TW-3 and Bour strains of trachoma cultivated in serial passage in HeLa 229 cells. Journal of Infectious Diseases I16, 390-399.

JENKIN, H. M. \& FAN, V.S. C. (I971). Contrast of glycogenesis of Chlamydia trachomatis and Chlamydia psittaci strains in HeLa cells. In Trachoma and Related Disorders, pp. 52-59. Edited by R. L. Nichols. Amsterdam: Excerpta Medica.

Johnson, F. W. A. \& Hobson, D. (I976). Factors affecting the sensitivity of replicating McCoy cells in the isolation and growth of Chlamydia A (TRIC agents). Journal of Hygiene 76, 44I-45I.

Kajima, M., Sharon, N. \& Pollard, M. (I967). Virus-like particles in cultures of McCoy cells. Journal of Ultrastructure Research $\mathbf{1 8}, 66 \mathrm{I}-666$.

Kramer, M.J. \& GoRdon, F. B. (197I). Ultrastructural analysis of the effects of penicillin and chlorotetracycline on the development of a genital tract Chlamydia. Infection and Immunity 3, 333-34I.

Kuo, C. C., Wang, S. P., Wentworth, B. B. \& Grayston, J. T. (1972). Primary isolation of TRIC organisms in HeLa 229 cells treated with DEAE-dextran. Journal of Infectious Diseases 125, 665-668.

Litwin, J., Officer, J. E., Brown, A. \& Moulder, J. W. (I96I). A comparative study of the growth cycles of different members of the psittacosis group in different host cells. Journal of Infectious Diseases I09, $251-279$.

Pollard, M. \& Starr, T. J. (1962). Study of intracellular virus with acridine orange fluorochrome. Progress in Medical Virology 4, 54-69.

RAKE, G. \& JoNES, H. P. (1942). Studies on lymphogranuloma venereum. I. Development of the agent in the yolk sac of the chicken embryo. Journal of Experimental Medicine 75, 323-338.

Richmond, S. J. (1974). The isolation of Chlamydia subgroup A (Chlamydia trachomatis) in irradiated McCoy cells. Journal of Medical Laboratory Technology 3r, 7-9.

RICHMOND, S. J. (1975). Chlamydia trachomatis in the human genital tract, pp. 48-50. M.D. thesis, Cambridge University.

RICHMOND, S. J. (1976). Growth of Chlamydia trachomatis in cell culture. Lancet i, 865.

Richmond, S. J. \& CAUL, E. O. (1975). Fluorescent antibody studies in chlamydial infections. Journal of Clinical Microbiology $\mathrm{x}, 345-352$.

Ridler, M. A. C. \& SMith, G. F. (I968). The response of human cultured lymphocytes to Cytochalasin B. Journal of Cell Science 3, 595-602.

Schachter, J., Dawson, C. R., Balas, S. \& Jones, P. (1970). Evaluation of laboratory methods for detecting acute TRIC agent infection. American Journal of Ophthalmology 7o, 375-380.

Sompolinsky, D. \& RICHMOND, S. (1974). Growth of Chlamydia trachomatis in McCoy cells treated with Cytochalasin B. Applied Microbiology 28, 912-9r4.

Sowa, J., Collier, L. H. \& Sowa, S. (I97I). A comparison of the iodine and fluorescent antibody methods for staining trachoma inclusions in the conjunctiva. Journal of Hygiene 69, 693-708.

Todd, W. J. \& Storz, J. (I975). Ultrastructural cytochemical evidence for the activation of lysosomes in the cytocidal effect of Chlamydia psittaci. Infection and Immunity 12, 638-646.

WANG, S. P. \& GRAYSTON, J. T. (197I). Studies on the identity of the 'fast' egg-killing chlamydia strains. In Trachoma and Related Disorders, pp. 322-336. Edited by R. L. Nichols. Amsterdam: Excerpta Medica.

WeIsS, E. \& Dressler, E. R. (1960). Centrifugation of rickettsiae and viruses onto cells and its effect on infection. Proceedings of the Society for Experimental Biology and Medicine 103, 691-695.

Wentworth, B. B. \& AleXANDer, E. R. (I974). Isolation of Chlamydia trachomatis by use of 5-iodo-2deoxyuridine-treated cells. Applied Microbiology 27, 912-9 I6. 